Article

\title{
Doing Good Better: Impure Altruism in Green Apparel Advertising
}

\author{
So Young Song ${ }^{1}(\mathbb{C})$ and Youn-Kyung Kim ${ }^{2, *}$ \\ 1 Department of Family and Consumer Sciences, Fashion Design and Merchandising, Illinois State University, \\ Normal, IL 61790-5060, USA; ssong13@ilstu.edu \\ 2 Department of Retail, Hospitality and Tourism Management, University of Tennessee, Knoxville, \\ TN 37996, USA \\ * Correspondence: ykim13@utk.edu; Tel.: +1-865-974-1025
}

Received: 16 September 2019; Accepted: 16 October 2019; Published: 17 October 2019

\begin{abstract}
In this study, we identify impure altruism as a duality of altruistic and egoistic warmth. We examine how these feelings motivate consumers to buy green apparel in response to advertisements. We test the effectiveness of the message orientation and its interactivity with a beneficiary and propose modeling impure altruism as the reason why consumers purchase green apparel. The study uses a quasi-experiment to estimate a comparison effect among advertising stimuli. We conduct an online survey among US consumers that garnered 586 responses for the main data analysis. The results indicate that egocentric appeals increase perceived uniqueness and that human beneficiary appeals lead to higher communal harmony. The findings show that communal harmony and global wellbeing prompt altruistic warmth and that uniqueness and product quality encourage egoistic warmth. Notably, altruistic warmth contributes to egoistic warmth, which indicates the existence of impurely altruistic consumers. Both altruistic and egoistic warmth lead to the intention of purchasing green apparel. We recommend "feel-good" marketing strategies to publicize the benefits of a sustainable lifestyle. The study contributes to the theoretical development of sustainability and can serve as an extension of a discrete model of altruism and egoism on consumers' sustainable behavior.
\end{abstract}

Keywords: advertising; altruism; apparel; egoism; environment; green marketing; impure altruism; sustainable fashion; sustainability; warmth

\section{Introduction}

The literature in social psychology and advertising suggests that consumers' sustainable purchases can be shaped by two emotional states: altruism and egoism [1,2]. Although the literature defines altruism as "a desire to benefit others' welfare" [3], there is a long-standing debate as to whether altruistic actions are driven purely by empathic concern for others or by egoistic self-interests. Pure altruism arises from altruistic warmth and includes sympathy, empathy, and compassion for others' wellbeing [4]. By contrast, egoism derives from self-interest and includes egoistic feelings of warmth such as pride and self-respect [5]. This egoistic feeling of warmth is called a "warm-glow" [6]. Impure altruism is the synchronicity between pure altruism and egoism [7]. That is, impure altruism comes from mixed motivations of a philanthropic value in altruistic acts and self-centered benefits of the emotional incentive obtained from social reputation and prestige [6]. To explain why an individual engages in impure altruism, we first examine the effectiveness and interactivity of two types of advertising: the message orientation (altercentric vs. egocentric) and the type of beneficiary (earth vs. human) on the perceptions of societal and personal benefits. We then conceptualize impure altruism as the duality of emotional warmth - altruistic and egoistic — and examine how these feelings motivate consumers to buy green apparel. In this study, the terms "pure altruism" and "altruism" are interchangeable. 
Increasing consumers' awareness about environmental and ethical issues has been a key goal of "green apparel" and social marketing aimed at sustainability [8-10]. In this study, green apparel reflects this key concept of sustainability and refers to apparel that is (1) manufactured with ecofriendly materials and processed with minimal environmental impact and (2) ethically sourced to improve poverty and working conditions for laborers. To identify effective green advertising strategy, the research has compared the influence of different appeal types, such as altercentric versus egocentric appeals and the environment versus human beneficiary in advertising claims. Altercentric messages appeal to collectivism by focusing on benefits to others, such as purchases that help reduce child labor and support local business, whereas egocentric messages appeal to personal or functional benefits, such as product attributes of green apparel that enhance the consumer's shopping experience. The type of advertising that focuses on the environment as the beneficiary stresses the advantage to the planet or nature conservation while the type that appeals to humans as the beneficiaries stresses the protection of human rights or wellbeing and health [11].

In fostering sustainable acts, firms have increasingly used these categories of advertising in their social marketing campaigns [1,12]. Yet, the research has not tested which appeal type more efficiently predicts consumers' perceptions of the benefits from purchasing green apparel or the interactivity of the appeal types. Along these lines, the first part of our research model tests the influence of the message orientation (altercentric vs. egocentric) and the type of beneficiary (earth vs. human) on perceived benefits of green apparel in an advertisement. In the second part of the research model, we examine the role of emotional warmth mediating the relationship between the perceived benefits and the intentions to purchase green apparel. We then test the duality of emotional warmth and conceptualize impure altruism in consumers' underlying reasons for their green purchases.

\section{Literature Review}

\subsection{Green Advertising Appeal Type}

Green advertising is advertising that discourses on the impact of a green product on the biophysical environment, promotes a green lifestyle, or shows corporate social responsibility $[8,10]$. To meet these criteria, firms can uniquely position advertising messages to elicit consumers' favorable perceptions of the benefit of a green product and its brand $[8,10]$. In this study, we use two categories of green appeals to explain the complex mechanism of why an individual engages in sustainable purchases and to illustrate the conception of impure altruism [13]: the message orientation (altercentric versus egocentric) and the beneficiary type (earth versus human).

\subsubsection{Message Orientation: Altercentric Versus Egocentric}

The first ad category is a message orientation. It consists of altercentric versus egocentric message appeal types. Altercentric appeals focus on how others benefit from prosocial behavior. The sentiments such as "we can help others" and "we can prevent abuse to others" would be examples of ad messages. Generally, altercentric appeals are effective at promoting honorable or benevolent behavior among individuals with altruistic motives $[9,13,14]$. In comparison, egocentric appeals focus on how the behavior benefits individuals propelled by receiving recognition or feeling good about themselves, for example, "our product will make you feel good about yourself." Research suggests that egocentric appeals can be viewed as more valuable among individuals with self-oriented motives than altercentric appeals [14]. We therefore postulate that the types of perceived benefits change according to the altercentric or egocentric orientation of the advertising appeal.

\subsubsection{Beneficiary Type: Human Versus Earth}

Research in altruism shows that the norm of reciprocity in which an individual can expect to receive reciprocal benefits from his or her altruistic act can motivate prosocial behavior [3]. Literature in sustainable behavior further suggests that consumers perceive a greater benefit from acts that help 
people compared to acts that help the environment $[9,15]$. This difference can be interpreted as in-group favoritism toward humans [15]. As a result, advertising messages about human beneficiaries (e.g., "when you buy our product, you support children's education") can facilitate a more positive evaluation and higher reciprocal value positioning than messages about the planet or environmental beneficiaries (e.g., keeping the environment clean) $[12,13,15]$. Thus, we propose that green advertising can be more effective when advertisements emphasize humans over the earth.

\subsection{Altruistic and Egoistic Motivation}

Motivation can be described as the reason for the behavior behind consumers' product choices to meet their needs [13]. Motivations for behaving sustainably can be categorized into two psychological states: altruism and egoism [2]. Altruism describes "true" philanthropic motivation, in which one responds with empathic concern for others without seeking a personal benefit [4]. Batson [3] defines altruism as "a motivational state with the ultimate goal of increasing another's welfare" (p. 20). Thus, an individual who purchases green products only to enhance the wellbeing of others falls into the altruistic category. By contrast, egoism is "a motivational state with the ultimate goal of increasing one's own welfare" [3]. As such, egoism is achieved when one pursues actions that benefit oneself or that offer personal rewards. Many psychological theories have asserted that all human motivation is inherently selfish [2,5]. Reflecting this egoistic view in sustainable behavior, when an individual seeks to attain self-gratification through serving his or her self-interests and welfare through purchasing green products (e.g., seeking aesthetic uniqueness of Fair Trade products, choosing organic children's wear and natural food for health and safety reasons), this individual falls into the egoistic category.

An argument over whether self-interest or other interests motivates altruistic behavior has been ongoing for the last two decades $[3,6,16]$. Scholars disagree about the existence of true altruism because others' welfare is not easily one's ultimate goal without expectations of reciprocity $[3,6,16]$. For example, Batson [3] argues: "Even if it were possible for a person to be motivated to increase another's welfare, such a person would be interested in attaining this desired goal and would experience pleasure in doing so" (p. 21). Cialdini et al. [16] counter that "the conditions that lead to empathic concern also lead to a greater sense of self-other overlap, raising the possibility that helping under these conditions is not selfless but is also directed toward the self" (p. 481). To explain this mixed category of altruistic and egoistic motivations, we borrow Andreoni's [6] theory of warm-glow giving and explore impure altruism as a psychological phenomenon that connects altruism to egoistic good feelings.

\subsection{Impure Altruism}

Andreoni's [6] theory of warm-glow giving defines two states of altruism: impure and pure. Impure altruism arises when a consumer is motivated by a combination of pure altruism and egoism to pursue both others' wellbeing and his or her personal welfare. Through acting sustainably, the consumer cherishes others and also seeks to increase his or her feelings of pride, self-respect, self-betterment, and social reputation. Feeling good about being a caring and ethical person can be a mighty incentive to purchase green products. Hence, impure altruism mixes an altruistic goal with egoistic pleasure [17]. We employ this phenomenon of impure altruism in green purchases that can explain why consumers engage in sustainable behavior. While Andreoni's [6] theory of warm-glow giving is about the provision of public goods, we are interested in the concept of green purchases in which sustainability is a feature of a personal good purchased for private consumption.

\subsection{Benefit Perception from Green Apparel Advertising}

Consumers perceive two types of benefits when purchasing green apparel: societal and personal [2]. Societal benefits focus on others: the community, the environment, and humanity as a whole [18]. Personal benefits relate to self-interests and individual goals: the functionality, design, and style of the apparel $[3,10,19]$. 


\subsubsection{Societal Benefit Perception}

Consumers occasionally engage in sustainable activities primarily to benefit others and to preserve nature even though their green choices can be more costly than choosing nongreen products [18]. These green consumers tend to place a greater weight on the societal values of sustainable products when making their purchase decisions. We classify these perceptions of societal benefit into two specific dimensions: communal harmony and global wellbeing.

\section{Communal Harmony}

In this study, communal harmony denotes the extent of "perceived understanding, appreciation, tolerance, protection, and preservation for the welfare of all people and for nature" [20] in response to advertising messages. In recent years, a growing body of evidence demonstrates a positive relation among communal harmony, altruistic purchasing behavior, and environmental concern [12,21,22]. For example, Pinto, Nique, Añaña, and Herter [23] analyze how consumers' values influence environmentally responsible water consumption in Brazil. They find that consumers who endorse higher societal values, such as communal harmony, tend to have stronger behavioral intentions to protect the environment compared to those who are less likely to endorse collective beliefs. This socially oriented worldview is an altruistic dimension of sustainable consumers [12,22]. Similarly, when consumers make green apparel purchases based on a sense of communal harmony, these actions are generally viewed as altruistic and as eliciting altruistic emotions. Thus, we propose that communal harmony is an essential cornerstone for the feeling of altruistic warmth in green advertising.

\section{Global Wellbeing}

Perceived global wellbeing describes the benefit of a healthy quality of life for all humanity. While wellbeing can be dedicated to an individual's physical and psychological welfare, this study defines global wellbeing as a society-wide concept of collective welfare [18]. Likewise, depending on the benefit focus of green advertising, individuals primed with an altercentric message are likely to perceive greater global wellbeing than individuals who are primed with an egocentric message [18]. Indeed, increased perceptions of global wellbeing from green advertising can facilitate consumers' altruistic feelings, their willingness to accept economic sacrifices to protect the earth, and their intentions to purchase sustainable products [21]. We thus explore the concept of global wellbeing as a societal benefit because the purchase of green apparel helps to improve environmental and social wellbeing.

\subsubsection{Personal Benefit Perception}

Most green advertisements have been directed to emphasizing societal or environmental attributes of green products to shape consumers' sustainable behavior [12]. However, such sustainability marketing has paid little attention to enhancing consumers' personal benefits, such as product functionality, quality, design, and style in its advertising strategy $[9,14]$. Such individual benefits help conscientious consumers make sustainable decisions to switch to green apparel from nongreen products $[19,24]$. We categorize the perception of the personal benefits of green apparel into two facets: uniqueness and product quality.

\section{Uniqueness}

In advertising, perceived uniqueness refers to "the extent to which consumers perceive the product in the advertisement as different from others" [25]. Consumers constantly seek distinctive styles and designs in clothing because of their desire for uniqueness [26]. The research has shown that consumers' demand for green products can also stem from their desire to be different from others or to own an item that arouses their self-expressive benefits in two ways: perceiving themselves as socially responsible and as fulfilling their role in society, and perceiving aesthetic uniqueness of green apparel products [19]. By purchasing green products, consumers can express their moral concerns about 
environmentally harmful production or unethical labor procedures and can thereby establish their identity as ethical people. When consumers see this contribution to society as a means of differentiating themselves from conventional shoppers, they are more likely to purchase green apparel. In this context, one way to promote wearing green apparel is to highlight, in advertising, a green product's uniqueness that enables consumers to express their individuality-perceived as a responsible and ecological citizen. While consumers generally have some preconception that sustainable apparel is not fashionable or stylish, there is evidence that product uniqueness and authentic designs tend to increase consumers' willingness to pay more for the ethical apparel products sold by Fair Trade [19]. Fair Trade apparel is culturally designed textile products and manufactured in developing countries, keeping authentic craftsmanship and cultural heritage alive. Therefore, Fair Trade offers a unique aesthetic advantage that enables consumers to express their individuality in the dress. The research has also shown that product ethnicity and the desire for individuality in clothing tend to form a favorable perception about appearance that exerts a positive influence on the purchasing intention of Fair Trade apparel [27]. In this case, embedding personal benefits such as originality of style in green advertising can be an effective strategy for promoting green apparel. Even in the secondhand clothing market, the uniqueness of clothing is one of the most influential factors that determine consumers' future purchasing intentions $[9,26]$. Clearly, uniqueness in green apparel can intrinsically motivate consumers by anticipating results that will personally benefit them and satisfy their desire for individuality.

\section{Product Quality}

Product quality is a consumer's perception of "intrinsic product characteristics such as product features, durability, and conformance quality, which refers to the degree to which a product meets its technical specifications" [28]. In this study, the quality of green apparel is a dimension of the functional benefits of clothing, such as durability, workmanship, material quality, and overall quality. Hartmann et al. [29] assert that a green branding strategy that focuses exclusively on societal benefits might have limited effectiveness without conveying functional benefits. In other words, when a consumer perceives a high level of functional quality in a product from a green advertisement, he or she deems the product useful in meeting his or her personal needs and wants. However, when a consumer perceives that the product in an advertisement is inferior, this perception can be a substantial barrier to purchases of green products [30]. In this case, consumers are likely to purchase alternative nongreen products that have better quality and that are compatible with their self-interests. If green advertising instead presents a marketing message that enhances the perceptions of quality in green products, consumers might view their purchases of this product as relatively more important and meaningful [1,9].

Based on the reasoning in the literature, we predict that consumers will evaluate the societal benefits of communal harmony and global wellbeing more positively when viewing an altercentric message orientation compared to an egocentric message. By contrast, consumers will evaluate the personal benefits of uniqueness and product quality more favorably when viewing an egocentric message orientation compared to an altercentric message. In terms of the beneficiary type, we posit that consumers will perceive higher levels of societal benefits of communal harmony and global wellbeing as well as personal benefits of uniqueness and product quality when viewing green advertisements that feature humans as the beneficiaries rather than those that feature the earth as the beneficiary. Therefore, we hypothesize the following associations:

H1. A green apparel ad with an altercentric message orientation will generate more positive perceptions of the societal benefits of communal harmony (H1a) and global wellbeing (H1b) than an ad with an egocentric message orientation.

H2. A green apparel ad with an egocentric message orientation will generate more positive perceptions of personal benefits of uniqueness ( $\mathrm{H} 2 a$ ) and quality $(\mathrm{H} 2 b)$ than an ad with an altercentric message orientation. 
H3. A green apparel ad with a human beneficiary will generate more positive perceptions of both the societal benefits of communal harmony (H3a) and global wellbeing ( $\mathrm{H} 3 b)$ and the personal benefits of uniqueness $(\mathrm{H} 3 \mathrm{c})$ and quality (H3d) than an ad with an earth beneficiary.

We also investigate the potential interactive effect between the message orientation and the beneficiary type in green advertising. Consumers tend to perceive their sustainable purchases as more valuable when they benefit people rather than nature or the planet [31]. Research in advertising shows that promotional messages are likely to be evaluated more favorably when they are consistent with consumers' personal values and egoistic consideration [31]. Since the benefit of self is more likely to increase consumers' overall evaluation of the advertisements and their green consumption behavior [1], we suppose that the differences in perceived benefits between the earth and the human beneficiary can be less apparent for an egocentric message orientation than for an altercentric message. However, when the green advertisement contains the altercentric message, an appeal with the human beneficiary might create more positive responses than an appeal with the earth beneficiary and, therefore, the difference in benefit perception could be more obvious. However, previous studies have not adequately examined the effect of green advertising based on its human versus earth beneficiaries $[9,15]$. Furthermore, there is limited information on how altercentric and egocentric appeals interact with these discrete beneficiary types on benefit perceptions. Due to this lack of supporting literature, we leave the hypothesis on the potential interaction effect as a bidirectional hypothesis. Therefore, we may hypothesize that:

H4. The effects of ad message orientation (altercentric vs. egocentric) on the societal benefits of communal harmony (H4a) and global wellbeing (H4b) and the personal benefits of uniqueness (H4c) and quality $(\mathrm{H} 4 \mathrm{~d})$ differ by beneficiary type of the ad (earth vs. human).

\subsection{Emotional Warmth}

We define emotional warmth as a spontaneous emotional response to warm feelings that an advertisement elicits [32]. Aaker et al. [33] develop an earlier definition of warmth as "a positive, mild, volatile emotion involving physiological arousal and precipitated by experiencing directly or vicariously a love, family, or friendship relationship" (p. 366). This expression of good-natured, charitable, kindly, and sincere feelings about an advertising stimulus encourages a consumer's benevolent actions and can predict his or her moral-social judgments such as evaluating a socially responsible product [34]. Since warmth can also guide consumers' brand attitudes, loyalty, and satisfaction, we embrace it as a way to describe the emotional responses that consumers experience when viewing green advertisements. In this study, we divide the warmth construct into two types of emotions elicited by advertising: altruistic warmth and egoistic warmth.

\subsubsection{Altruistic Warmth}

Altruistic warmth can be defined as an emotional expression of warm feelings, empathy, sympathy, compassion, care, and concern for others [33]. Altruistic warmth is about doing good, and it is motivated by wanting to care for others purely for others' benefit and not to benefit the self. This truly other-oriented emotion, derived from a sense of collectivism and altruism, can be distinguished from the egoistic warmth that comes from personal contentment or self-interest [1,22]. When consumers perceive greater other-oriented benefits in response to a green stimulus, they are more likely to experience a high level of altruistic warmth. Consistent with this concept, we anticipate that consumers who perceive a high level of societal benefits-such as communal harmony (H5a) and global wellbeing (H5b) - from green advertising are more likely to feel altruistic warmth.

H5. The perceived societal benefit of communal harmony ( $\mathrm{H} 5 \mathrm{a}$ ) and global wellbeing (H5b) will positively affect altruistic warmth. 


\subsubsection{Egoistic Warmth}

As previously defined, egoistic warmth derives from altruistic acts that elicit pleasurable and self-centered feelings of pride, self-gratification, contentment, and self-respect [6]. In contrast to altruistic warmth, egoistic warmth relies on personal benefits [17]. Some researchers assert that sustainable consumption perpetually occurs when green products are associated with other-oriented benefits and altruistic emotions [35]. Others argue that providing an egoistic emotional benefit is more suitable for encouraging green consumption [5].

Advertising researchers typically argue that self-centered benefits are positively associated with egoistic message orientations [31]. Consumers who are motivated by personal needs and aspirations, such as uniqueness and product quality, are more likely to view the outcome of an altruistic action as important, and they eventually sense a high level of positive emotion [17]. Hence, we speculate that consumers' feelings of egoistic warmth increase when they perceive added values of uniqueness (H6a) and quality (H6b) from green products:

H6. The perceived personal benefits of uniqueness (H6a) and product quality (H6b) will positively affect consumers' egoistic warmth.

\subsection{Duality of Emotional Warmth and Purchase Intention}

Despite the importance of understanding the motives behind green consumption, researchers have been unable to determine how people are affected by pure and impure motives in their purchasing behavior $[7,17]$. The literature provides some evidence for the co-existence of altruism and egoism $[3,6,7]$. For instance, Andreoni [6] notes that an individual engaging in impure altruism is not only motivated by the welfare of the recipients of altruism but also receives additional utility from the altruistic act in the form of a warm-glow (i.e., egoistic warmth). Batson [3] also explains that egoistic emotions can arise when consumers have dual motives (e.g., to benefit others and themselves), even if they are altruistically motivated to engage in socially responsible acts. This duality explains the possibility of synchronized altruistic and egoistic warmth in the purchase of green apparel. Correspondingly, the consumers who purchase green apparel might feel two types of emotions jointly: altruistic warmth contributing to egoistic warmth. Altruistic feelings, such as compassion and empathy, are positively related to egoistic feelings, such as pride. Moreover, self-conscious and egoistic feelings are positively related to prosocial behaviors [7]. As the main goal of green products is to improve environmental and ethical issues, we start from the directionality of altruistic feeling contributing to egoistic feeling. Grounded in the notion of a warm-glow [6], we intend to describe the egoistic feeling like an additional utility, and propose that altruistic warmth will contribute to egoistic warmth such that pure altruism unavoidably influences egoistic emotion. By testing the duality of emotional warmth, we conceptualize impure altruism in consumers' responses to green advertising. We thus formulate the following hypothesis:

H7. Altruistic warmth will positively contribute to egoistic warmth.

Researchers find that consumers who feel the emotional warmth from an advertisement tend to show an increased level of optimistic attitudes toward a brand, personal satisfaction, and loyalty [34]. Therefore, it is reasonable to expect that they are likely to purchase green apparel in response to elevated levels of these positive emotions. These feelings promote both individual and collective wellbeing and ultimately facilitate sustainable actions [36]. Thus, we posit that:

H8. Altruistic warmth will positively affect consumers' purchasing intentions.

H9. Egoistic warmth will positively affect consumers' purchasing intentions. 


\section{Methods}

\subsection{Research Design}

We tested a conceptual model composed of two submodels. Submodel (A) was designed as a $2 \times 2$ factorial design with four groups (altercentric vs. egocentric and earth vs. human). A quasi-experiment (with no control group) was conducted to estimate a comparison effect between the message orientation and the type of beneficiary on four dependent variables (societal benefits of communal harmony and global wellbeing; personal benefits of uniqueness and product quality) [37]. In submodel (B), we investigated the relation between benefit perceptions, emotional warmth (altruistic warmth and egoistic warmth) and purchase intentions for green apparel products. We conducted a structural equation model (SEM) to conceptualize impure altruism.

\subsection{Pretest and Manipulation Checks}

Eight advertisements were utilized in this quasi-experiment. The message orientation was manipulated by textual priming, using either "We" (for altercentric: "We can preserve our earth" or "We can help others") or "I" (for egocentric: "I can enjoy my favorite denim" or "It helps me to be a better person"). Two beneficiary types of advertising were developed using visual and message priming that focused on the earth and environment ("to preserve our earth," or "to keep my environment clean") or on human beneficiaries ("to care about children and improve workers' health"). Each level of advertisements in the $2 \times 2$ factorial design described two directions of either enhancing promotion or prevention-regulatory focused aspects of the outcome related to sustainability that reflected the common variation in advertising appeals [11]. The promotion-focused message was developed by contextually emphasizing the positive benefits of wearing green apparel (e.g., "great way," or "gives me a great opportunity"). The prevention-focused message describes avoiding negative outcomes caused by environmental harm or unethical production (e.g., "suffering," or "harm by toxic pollutants"). This regulatory focus factor (promotion or prevention) in the advertisements was tested prior to the main data analysis and was verified as having no significant main effects and interaction effects on any variables in this study (see the Results section).

We conducted a content analysis of the eight stimuli for valid manipulation and carried out a pretest. Prior to the pretest, four researchers in consumer sciences implemented the first content analysis of textual and visual elements in the advertisements. Subsequently, preliminary versions of the advertisements were pretested to refine the stimuli. We collected 202 pretest samples from undergraduate students in a consumer behavior course using a snowball sampling technique. Of those, 134 responses were usable for the pretest analysis after excluding 36 incomplete responses. Using a 7-point Likert scale, the pretest respondents were asked to estimate their agreement with the ad rating statements whether the preliminary advertisements represented the intended message types (message orientation, beneficiary type, and promotion/prevention-regulatory focus) [9]. They were given the following example statements [9]: (1) "the ad message is related to the environment for all of us and others" (i.e., altercentric/earth); (2) "the ad message is related to all human being and others' welfare" (i.e., altercentric/human); (3) "the ad message is related to protecting the earth or environment" (i.e., earth/prevention); (4) "the ad message is related to promoting human health" (i.e., human/promotion); (5) "the ad message is related to the environmental issue that is relevant to $m e$ " (i.e., egocentric/earth); and (6) "the ad message is related to the human welfare issue that is relevant to $m e^{\prime \prime}$ (i.e., egocentric/human). The mean scores were greater than a 4-point level $(4=$ neither agree nor disagree $)$ for all types of preliminary advertising stimuli (ranged from 4.4 to 6.0 out of 7). Based on suggestions from the pretest respondents, the messages contained in the eight advertisements were revised. Afterward, 1 researchers conducted a second content analysis for stimuli. Multiple revisions of the advertising messages and the layout of stimuli followed to improve the clarity of the advertising appeals before conducting the main data collection. Table 1 provides the final versions of the advertising messages used in the main study. 
Table 1. Types of green advertising messages.

\begin{tabular}{|c|c|c|c|c|}
\hline Ad Stimuli & Beneficiary Type & Message Orientation & Regulatory Focus & Advertising Messages \\
\hline Ad 1 & Earth & Altercentric "We" primed & Promotion & $\begin{array}{l}\text { Wearing sustainable blue jeans is a great way to keep our } \\
\text { environment clean and beautiful, naturally. We can preserve our } \\
\text { earth by wearing eco clothing-“Green" Jeans. }\end{array}$ \\
\hline Ad 3 & Human & Altercentric "We" primed & Promotion & $\begin{array}{l}\text { Wearing sustainable blue jeans is a great way to care about children, } \\
\text { and improve workers' health in production countries. We can help } \\
\text { others by wearing ethically sourced, ethically made and ethically } \\
\text { distributed clothing products_-“Green” Jeans. }\end{array}$ \\
\hline Ad 4 & Human & Altercentric "We" primed & Prevention & $\begin{array}{l}\text { Wearing sustainable blue jeans helps stop child labor, and prevents } \\
\text { workers' health from suffering in production countries. We can } \\
\text { prevent abusing others by wearing ethically sourced, ethically made } \\
\text { and ethically distributed clothing-“Green" Jeans. }\end{array}$ \\
\hline Ad 5 & Earth & Egocentric "I" primed & Promotion & $\begin{array}{l}\text { Wearing sustainable blue jeans is a great way to keep my } \\
\text { environment clean and beautiful, naturally. I can enjoy my favorite } \\
\text { denim and care for my earth by wearing eco clothing-“Green” Jeans. }\end{array}$ \\
\hline Ad 6 & Earth & Egocentric "I" primed & Prevention & $\begin{array}{l}\text { Wearing sustainable blue jeans helps protect my environment from } \\
\text { the harm of toxic pollutants. I can protect my earth from being } \\
\text { destroyed by wearing eco clothing-“Green” Jeans. }\end{array}$ \\
\hline Ad 7 & Human & Egocentric "I" primed & Promotion & $\begin{array}{l}\text { Wearing sustainable blue jeans gives me a great opportunity to } \\
\text { promote ethical purchasing, and helps me to be a better person than I } \\
\text { was yesterday. I can enjoy my favorite denim by wearing ethically } \\
\text { sourced, ethically made and ethically distributed clothing } \\
\text { products_-"Green" Jeans. }\end{array}$ \\
\hline Ad 8 & Human & Egocentric "I" primed & Prevention & $\begin{array}{l}\text { By wearing my sustainable blue jeans, I stop making selfish and } \\
\text { unethical purchasing. I fight against unethical production. I prevent } \\
\text { wrongdoings by wearing ethically sourced, ethically made and } \\
\text { ethically distributed clothing products-“Green” Jeans. }\end{array}$ \\
\hline
\end{tabular}


To ensure that the successful manipulation of advertisements in the main data collection, the main survey respondents were given the same ad rating statements as the pretest and were asked to rate their perception of an advertisement by using a 7-point Likert scale [9]. For the main data analysis, we used a stricter cutoff point than the pretest (4-point level cutoff) and included only those respondents who answered these questions at greater than or equal to a 5-point level $(5=$ "somewhat agree" to $7=$ "strongly agree"). A total of 586 responses were retained for the final data analysis.

\subsection{Main Data Collection and Procedure}

To test the research model (Figure 1), we conducted an online survey among US consumer panelists of a marketing firm and participants were recruited via an e-mail invitation to complete a survey. Each participant was paid $\$ 3$ in credits to the earning account for compensation after completion of the online survey. Participants needed to be 18 years or older, and they must have purchased a green product (e.g., environmentally friendly, recycled, reclaimed, sweatshop-free, Fair Trade, organic, animal-friendly, wildlife-friendly) during the six months prior to their completing the survey. Participants were randomly assigned to a version of the eight stimuli followed by questionnaires. As a result, the study groups had the same chance of being assigned to a given experiment stimulus, which ensured that the two levels of experimental groups were equivalent [37].

The study was reviewed and approved by the Institutional Review Board (IRB) and was exempted from a review of human subjects. A total of 829 responses were collected for a period of 4 days. After the manipulation check, 586 responses were retained and used for the main data analysis (see the Results section). The analysis of the respondents' demographic information showed that gender was evenly distributed ( $57.3 \%$ female and $42.7 \%$ male). The participants were widely distributed along the income spectrum with a median annual household income of $\$ 60,000-\$ 79,999$. Participants' ages ranged from 18 to 84 , with an average age of 41 . In terms of ethnicity, the majority were Caucasians $(59.6 \%)$, followed by African-Americans (17.4\%), then Hispanics and Latino-Americans (14.3\%).

\subsection{Measures}

The measures of this study were modified from existing scales to reflect our experiment context. Specifically, communal harmony scale items were adopted from Schwartz [20]; global wellbeing items from Chang [38] and Adams, et al. [39]; uniqueness items from Argo, et al. [40] and Kim, et al. [41]; product quality items from Chandrashekaran [42] and Grewal, et al. [43]; altruistic warmth items from Aaker et al. [44]; egoistic warmth items from Rosenberg [45] and Shiota, et al. [46]; and purchase intention items from Dodds, et al. [47]. All items of these seven constructs were measured on a 7-point Likert-type scale, anchored by "strongly disagree" (1) and "strongly agree" (7). The content analysis of the survey items was conducted by ten researchers in the consumer science field. The survey items were revised for clarity and readability based on these researchers' comments.

\section{Results}

The hypothesized model comprises submodels (A) $2 \times 2$ ANOVAs and (B) SEM and involves a two-step data analysis. We first evaluated the adequacy of measurements using confirmatory factor analysis (CFA). We then tested the hypothesized relationships depicted in our research model (Figure 1). The CFA and the SEM analyses for the submodel (B) were conducted with Mplus 7.31, and the parameters were estimated using the maximum likelihood method. The model's fit was tested with the $\chi^{2} / \mathrm{df}$ ratio, comparative fit index (CFI), Tucker-Lewis index (TLI), root mean square error of approximation (RMSEA), and the standardized root mean square residual (SRMR) [48]. 


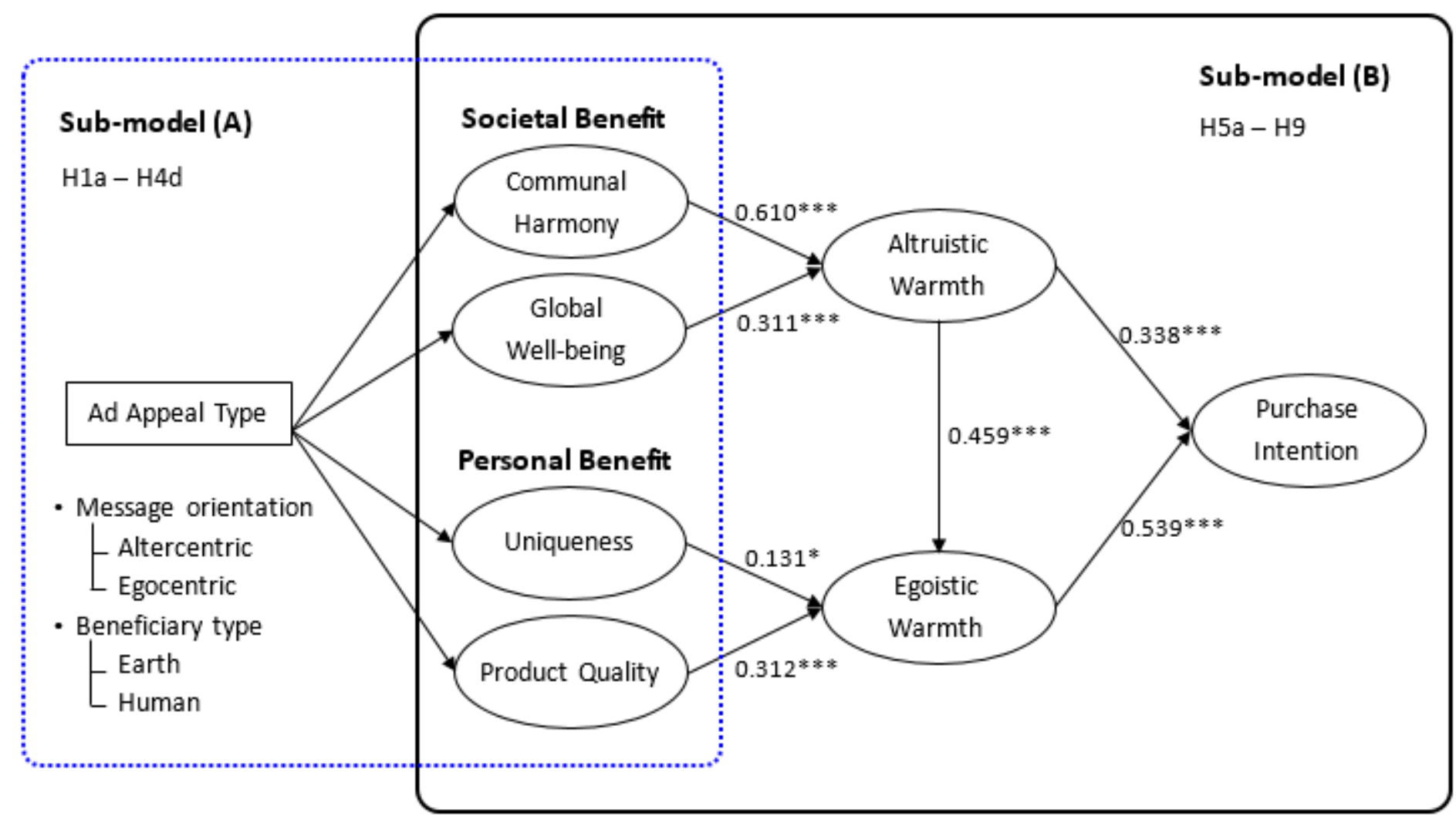

Figure 1. Research model. Submodel (B) SEM fit indices: $\chi^{2}(616)=2738.350, p<0.001$; comparative fit index (CFI) $=0.922$; Tucker-Lewis index (TLI) $=0.916$; RMSEA $=0.077$; SRMR $=0.049 ;{ }^{*} p<0.05,{ }^{* *} p<0.01,{ }^{* * *} p<0.001$. 


\subsection{Measurement Model Results}

The results of the CFA indicated that our measurement model had a good fit [48]: $\chi 2(608)=2411.209$, $p<0.001 ; \mathrm{CFI}=0.934 ; \mathrm{TLI}=0.927 ; \mathrm{RMSEA}=0.071 ;$ and SRMR $=0.032$. All items had standardized factor loadings that ranged from 0.780 to 0.947 . The construct validities of the latent constructs were evaluated with convergent and discriminant validities. The convergent validity was confirmed by these findings. All path weights were significant $(p<0.001)$. The composite reliabilities of all constructs ranged from 0.876 to 0.974 , which met the minimum criteria of 0.70 [49]. The values of average variances extracted (AVEs) for all latent variables were greater than the threshold value of 0.50 [50], and ranged from 0.691 to 0.872 . The discriminant validity was confirmed by the AVE values, which were greater than the shared variance between all possible pairs of latent variables [50]. Table 2 presents the results of the CFA.

Table 2. Measures: CFA Result $(n=586)$.

\begin{tabular}{|c|c|c|}
\hline Scale Items & Factor Loading & Composite Reliability \\
\hline Communal Harmony & & 0.974 \\
\hline would help justice for every person in the world be treated equally & 0.892 & \\
\hline would help me to listen to people who are different from me & 0.915 & \\
\hline would help me to live in harmony with the world's people & 0.916 & \\
\hline would help me to protect the weak in society & 0.911 & \\
\hline would help me to care for other people & 0.932 & \\
\hline would help me to devote myself to people in our society & 0.926 & \\
\hline would help me to respond to the needs of others & 0.924 & \\
\hline Global wellbeing & & 0.939 \\
\hline would benefit healthy living in natural environments & 0.821 & \\
\hline would help improve the quality of life in healthy environments & 0.880 & \\
\hline would help provide positive global health impacts & 0.866 & \\
\hline would help reduce environmental threat that can potentially affect human health & 0.875 & \\
\hline would help prevent environmental pollution that can be harmful to human health & 0.836 & \\
\hline would help provide a safe environment and better human health & 0.816 & \\
\hline Uniqueness & & 0.899 \\
\hline appears to be unique & 0.780 & \\
\hline appears to be distinctive & 0.851 & \\
\hline appears to be different than others have & 0.832 & \\
\hline appears to be special & 0.860 & \\
\hline Product Quality & & 0.927 \\
\hline appears to be of good quality & 0.848 & \\
\hline appears to last for a reasonably long period of time & 0.860 & \\
\hline appears to be good in the workmanship & 0.889 & \\
\hline appears to be manufactured with quality materials & 0.890 & \\
\hline Altruistic Warmth & & 0.966 \\
\hline caring & 0.839 & \\
\hline tender & 0.917 & \\
\hline empathetic & 0.811 & \\
\hline warm & 0.913 & \\
\hline sentimental & 0.897 & \\
\hline emotional & 0.863 & \\
\hline sympathetic & 0.811 & \\
\hline warmhearted & 0.913 & \\
\hline affectionate & 0.864 & \\
\hline Egoistic Warmth & & 0.971 \\
\hline would help me to feel better about myself & 0.914 & \\
\hline would help me to feel more proud of myself & 0.922 & \\
\hline would help me to have more respect for myself & 0.956 & \\
\hline would enhance my self-esteem. & 0.929 & \\
\hline would help me to have a more positive attitude toward myself & 0.947 & \\
\hline Purchase Intention & & 0.876 \\
\hline I have a likelihood of purchasing the product in this ad & 0.862 & \\
\hline I would buy the product in this ad in the future & 0.903 & \\
\hline
\end{tabular}

Note. Model fit: $\chi^{2}(608)=2411.209, p<0.001 ;$ CFI = 0.934; TLI = 0.927; RMSEA = 0.071. 


\subsection{Submodel (A) Results}

\subsubsection{One-Way ANOVAs}

One-way ANOVAs were conducted to show that there were no significant main effects and interaction effects of the regulatory focus factor (promotion/prevention). The main effects of regulatory focus factor on all variables were not significant (i.e., communal harmony $F(1,578)=0.880, p>0.05$; global wellbeing $F(1,578)=0.017, p>0.05$; uniqueness $F(1,578)=3.053, p>0.05$; product quality $F(1$, $578)=0.703, p>0.05)$. The interaction effects between the regulatory focus and other ad types were not significant ( $F$ ranged from 0.012 to $0.700, p>0.05$ ). Accordingly, the effects of the regulatory focus factor were verified as insignificant on four variables of benefit perceptions and were combined as the common variation in advertising appeals.

\subsubsection{Two-Way ANOVA}

To test $\mathrm{H} 1$ a to $\mathrm{H} 4 \mathrm{~d}$, we conducted two-way ANOVAs of the message orientation and the beneficiary type on each dependent variable for the four benefit perceptions. Due to there being multiple analyses, we used the Bonferroni adjustment to maintain an experiment-wise type I error rate of $\alpha=0.05$ [51]. With this adjustment, an F-statistic was considered to be statistically significant only if its $p$-value was less than 0.0125 [51]. Using this criterion, the results of the two-way ANOVAs yielded a significant interaction effect between the message orientation type and the beneficiary type on product quality $(F(1,582)=8.442, p<0.01)(\mathrm{H} 4 \mathrm{a} / \mathrm{b} / \mathrm{c}$ are rejected; $\mathrm{H} 4 \mathrm{~d}$ is supported $)$. Therefore, an analysis of the simple main effect of the beneficiary type within message orientation on product quality was performed, along with pairwise comparisons. The simple main effect of the beneficiary type, within the altercentric message orientation, on product quality was significant $(F(1,582)=18.733, p<0.001)$, whereas the simple main effect within the egocentric message orientation was insignificant $(F(1,582)=0.025$, $p>0.05)$. The human beneficiary had a mean score of 0.566 for product quality $(95 \% \mathrm{CI}, 0.309$ to 0.823 , $p<0.001)$ that was higher than the earth beneficiary when the advertisements were directed toward an altercentric appeal only. Therefore, the main effects of the message orientation and the beneficiary type on product quality will not be discussed further ( $\mathrm{H} 2 \mathrm{~b}$ and $\mathrm{H} 3 \mathrm{~d}$ are rejected) (Table 3). The interaction effect on product quality is graphed in Figure 2.

The main effect of message orientation on uniqueness was significant, $F(1,582)=6.590, p<0.0125$. As predicted, an egocentric appeal was associated with a mean score of 0.227 for uniqueness $(95 \%$ CI, 0.053 to 0.400 ), which were higher than those for an altercentric appeal (statistically significant differences, $p<0.0125)$. Thus, $\mathrm{H} 2 \mathrm{a}$ is supported. However, the main effects of appeal orientation on communal harmony $(F(1,582)=2.695, p>0.0125)$ and global wellbeing $(F(1,582)=4.848, p>0.0125)$ were not significant. Hence, $\mathrm{H} 1 \mathrm{a}$ and $\mathrm{H} 1 \mathrm{~b}$ are rejected. Furthermore, the main effect of the beneficiary type on communal harmony $(F(1,582)=46.803, p<0.001)$ was significant, while the effects of global wellbeing $(F(1,582)=0.017, p>0.0125)$ and uniqueness $(F(1,582)=3.854, p>0.0125)$ were not. Thus, $\mathrm{H} 3 \mathrm{~b}$ and $\mathrm{H} 3 \mathrm{c}$ are rejected. As expected, a human beneficiary was associated with a mean score of 4.99 for communal harmony, which was significantly higher than that for an earth beneficiary (mean difference $=0.835 ; 95 \%$ CI, 0.595 to $1.075 ; p<0.001)$. Hence, H3a is supported. Table 3 summarizes these two-way ANOVAs results. 
Table 3. Two-way ANOVAs results: submodel (A).

\begin{tabular}{|c|c|c|c|c|c|c|c|c|c|}
\hline \multirow{3}{*}{ Criterion Variable } & \multicolumn{4}{|c|}{ Ad Appeal Type Group Means (SD) } & \multirow{3}{*}{ Source Variability } & \multirow{3}{*}{ SS } & \multirow{3}{*}{ MS } & \multirow{3}{*}{$F(1,582)$} & \multirow{3}{*}{$p$} \\
\hline & \multicolumn{2}{|c|}{ Message Orientation } & \multicolumn{2}{|c|}{ Beneficiary Type } & & & & & \\
\hline & Altercentric & Egocentric & Earth & Human & & & & & \\
\hline \multirow{3}{*}{ Communal harmony } & \multirow{3}{*}{$\begin{array}{c}4.47 \\
(0.09)\end{array}$} & \multirow{3}{*}{$\begin{array}{c}4.67 \\
(0.09)\end{array}$} & \multirow{3}{*}{$\begin{array}{c}4.15 \\
(0.08)\end{array}$} & \multirow{3}{*}{$\begin{array}{c}4.99 \\
(0.09)\end{array}$} & Orientation $(\mathrm{O})$ & 5.86 & 5.86 & 2.70 & 0.101 \\
\hline & & & & & Beneficiary (B) & 101.71 & 101.71 & $46.80 * *$ & 0.000 \\
\hline & & & & & $(\mathrm{O}) \times(\mathrm{B})$ & 9.92 & 9.92 & 4.56 & 0.033 \\
\hline \multirow{3}{*}{ Global wellbeing } & \multirow{3}{*}{$\begin{array}{c}5.28 \\
(0.07)\end{array}$} & \multirow{3}{*}{$\begin{array}{c}5.48 \\
(0.07)\end{array}$} & \multirow{3}{*}{$\begin{array}{c}5.39 \\
(0.06)\end{array}$} & \multirow{3}{*}{$\begin{array}{c}5.38 \\
(0.07)\end{array}$} & Orientation $(\mathrm{O})$ & 6.08 & 6.08 & 4.85 & 0.028 \\
\hline & & & & & Beneficiary (B) & 0.02 & 0.02 & 0.01 & 0.907 \\
\hline & & & & & $(\mathrm{O}) \times(\mathrm{B})$ & 5.89 & 5.89 & 4.69 & 0.031 \\
\hline \multirow{3}{*}{ Uniqueness } & \multirow{3}{*}{$\begin{array}{c}5.27 \\
(0.06)\end{array}$} & \multirow{3}{*}{$\begin{array}{c}5.49 \\
(0.06)\end{array}$} & \multirow{3}{*}{$\begin{array}{c}5.3 \\
(0.06)\end{array}$} & \multirow{3}{*}{$\begin{array}{c}5.46 \\
(0.06)\end{array}$} & Orientation $(\mathrm{O})$ & 7.51 & 7.51 & $6.59 *$ & 0.011 \\
\hline & & & & & Beneficiary (B) & 3.85 & 3.85 & 3.38 & 0.066 \\
\hline & & & & & $(\mathrm{O}) \times(\mathrm{B})$ & 5.71 & 5.71 & 5.02 & 0.026 \\
\hline \multirow{3}{*}{ Product quality } & \multirow{3}{*}{$\begin{array}{c}4.99 \\
(0.07)\end{array}$} & \multirow{3}{*}{$\begin{array}{c}5.31 \\
(0.07)\end{array}$} & \multirow{3}{*}{$\begin{array}{c}5.0 \\
(0.07)\end{array}$} & \multirow{3}{*}{$\begin{array}{c}5.30 \\
(0.07)\end{array}$} & Orientation $(\mathrm{O})$ & 15.32 & 15.32 & $11.95^{*}$ & 0.001 \\
\hline & & & & & Beneficiary (B) & 12.56 & 12.56 & $9.80 *$ & 0.002 \\
\hline & & & & & $(\mathrm{O}) \times(\mathrm{B})$ & 10.82 & 10.82 & $8.44 *$ & 0.004 \\
\hline
\end{tabular}

Note. $N=586 . S D=$ standard deviation, $S S=$ sum of squares; $M S=$ mean square; With Bonferroni adjustment, an $F$-statistic was considered to be statistically significant at $p$-value 0.0125 ; ${ }^{*} p<0.0125,{ }^{* *} p<0.001$. 


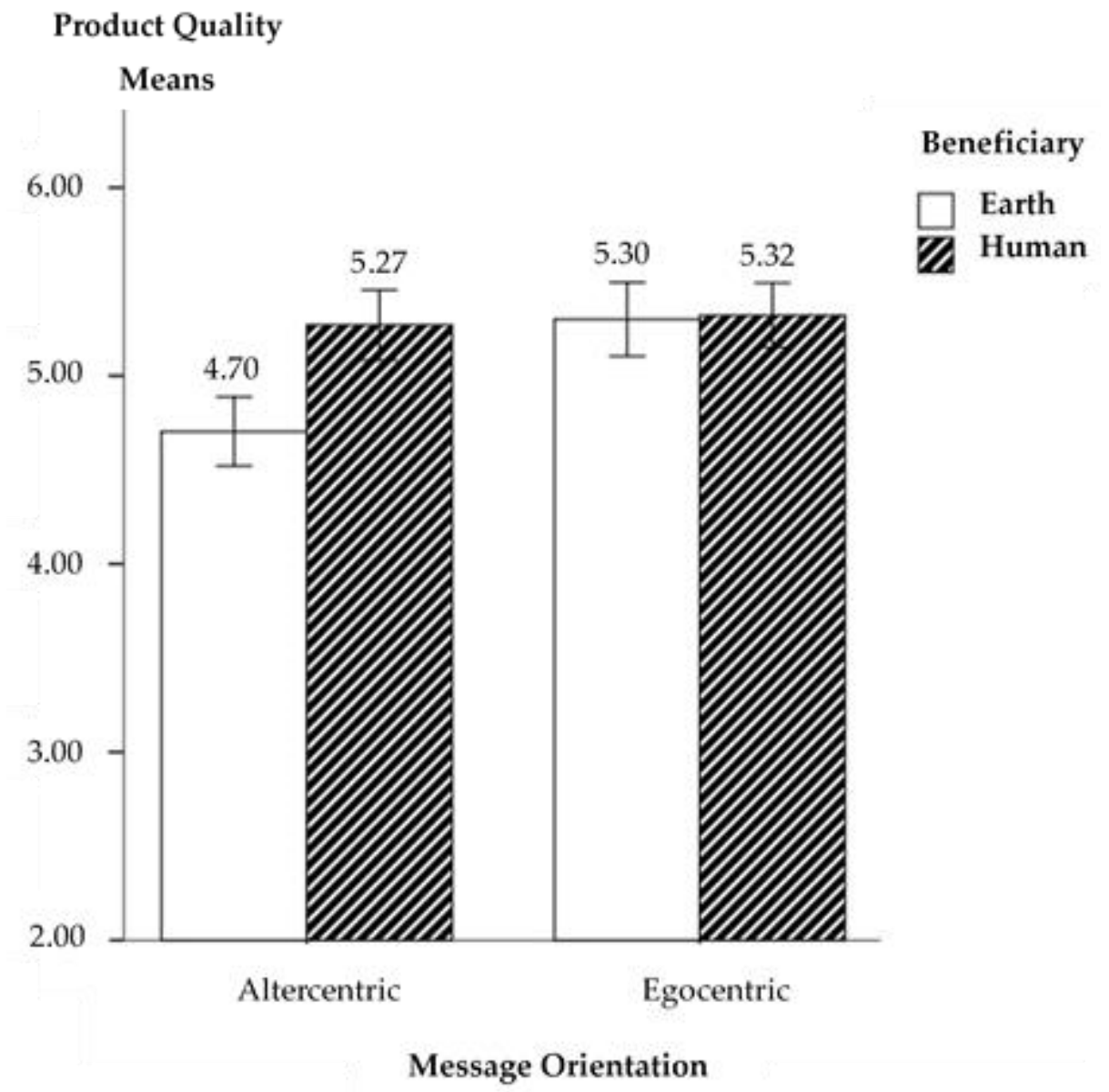

Figure 2. Interaction effect: product quality perception in response to appeal type.

\subsection{Submodel (B) Structural Model Results}

The results of the SEM supported the relationships depicted in submodel $(B): \chi^{2}(616)=2738.350$, $p<0.001 ; \mathrm{CFI}=0.922 ; \mathrm{TLI}=0.916 ; \mathrm{RMSEA}=0.077$; and SRMR $=0.049$. All path coefficients were significant $(p<0.05)$, supporting all of the hypothesized relationships in the structural model ( $\mathrm{H} 5-\mathrm{H} 9$ : see Figure 1). Specifically, altruistic warmth was significantly influenced by communal harmony $(\beta=0.610, p<0.001 ; \mathrm{H} 5 \mathrm{a})$ and global wellbeing $(\beta=0.311, \mathrm{p}<0.001 ; \mathrm{H} 5 \mathrm{~b})$. Egoistic warmth was significantly affected by uniqueness $(\beta=0.131, \mathrm{p}<0.05$; H6a) and product quality $(\beta=0.312, p<0.001$; H6b). In turn, altruistic warmth considerably influenced egoistic warmth $(\beta=0.459, p<0.001)$, which supported the posited mechanism of impure altruism (H7). Finally, we found that both altruistic warmth $(\beta=0.338, p<0.001 ; \mathrm{H} 8)$ and egoistic warmth $(\beta=0.539, p<0.001 ; \mathrm{H} 9)$ had significant and positive effects on purchasing intentions. Table 4 summarizes the results from submodel (B). 
Table 4. Submodel (B): SEM hypotheses testing.

\begin{tabular}{|c|c|c|c|c|}
\hline Hypotheses & Structural Paths & Standardized Estimate & Standard Error & z-value \\
\hline $\mathrm{H} 5 \mathrm{a}$ & Communal harmony $\rightarrow$ Altruistic warmth & 0.610 & 0.031 & $19.528^{* * *}$ \\
\hline $\mathrm{H} 5 \mathrm{~b}$ & Global wellbeing $\rightarrow$ Altruistic warmth & 0.311 & 0.034 & $9.169^{* * *}$ \\
\hline Hypotheses & Structural Paths & Standardized Estimate & Standard Error & z-value \\
\hline $\mathrm{H} 5 \mathrm{a}$ & Communal harmony $\rightarrow$ Altruistic warmth & 0.610 & 0.031 & $19.528^{* * *}$ \\
\hline $\mathrm{H} 6 \mathrm{~b}$ & Product quality $\rightarrow$ Egoistic warmth & 0.312 & 0.067 & $4.661^{* * *}$ \\
\hline $\mathrm{H} 7$ & Altruistic warmth $\rightarrow$ Egoistic warmth & 0.459 & 0.040 & $11.345^{* * *}$ \\
\hline H8 & Altruistic warmth $\rightarrow$ Purchase intention & 0.338 & 0.048 & $7.052^{* * *}$ \\
\hline H9 & Egoistic warmth $\rightarrow$ Purchase intention & 0.539 & 0.046 & $11.657^{* * *}$ \\
\hline
\end{tabular}

\section{Discussion and Implications}

We present theoretical and empirical analyses of altruism, egoism, and impure altruism and test the effectiveness and interactivity of the message orientation and the type of beneficiary in green apparel advertising. Based on Andreoni's [6] theory of warm-glow giving, we rationalize the existence of impurely altruistic consumers whose motivations stem from both altruistic and egoistic warmth. The results of the current study support the concept of impure altruism.

Advertisements that are strategically designed to elicit both altruistic and egoistic warmth can be particularly effective in influencing consumers' intentions to purchase green products $[2,3,10,18,19]$. Appeals to human beneficiaries in advertising can help consumers to perceive a social good. Furthermore, when a firm promotes green products in an altruistic direction with human-centered appeals (i.e., human wellbeing and health), this promotion can enhance consumers' perceptions of product quality. In addition, including egocentric messages in green advertising can improve the effectiveness of marketing by delivering a distinct product appeal to consumers.

Our findings indicate that consumers perceive greater personal benefit from uniqueness when they view an egocentric appeal than when they view an altercentric appeal. In contrast to our hypotheses, when viewing an altercentric advertisement, we do not find that the perceived societal benefits of communal harmony and global wellbeing are superior. Despite no statistical significance in these two variables, egocentric appeals consistently show higher means than altercentric appeals in the societal benefits. In other words, consumers do not perceive greater societal benefits in altercentric advertisements, even if the advertising appeals mainly emphasize collective advantage. Rather, they evaluate egocentric appeals as more important than altercentric appeals for both types of benefit perceptions. When a firm strategically designs its advertisements to enhance the uniqueness of its green products, an egocentric appeal aligns better with consumers' considerations of green purchases. As such, the value of a product offered by green advertising must be assessed to improve the advertisement's effect on consumers in a personal context focusing on functionality, design, and style of the apparel $[3,10,19]$. In other words, advertisers must answer the consumer's question, "What's in it for me?"

Next, our results indicate that appeals to human beneficiaries have more favorable effects than appeals to the earth on the societal benefit of communal harmony. When a firm strategically intends to promote social responsibility with a goal of promoting a positive corporate image from a collectivism standpoint, we recommend that advertisers use a human-centered approach in the design of their advertising appeals, rather than an environment-centered approach [9]. Thus, advertising messages can promote a more positive evaluation of green apparel than messages solely focusing on environmental beneficiaries [12,15].

Notably, the result of the interaction effect between the message orientation and the beneficiary type shows that appeals to human beneficiaries produce higher perceived product quality than 
environmental appeals when the advertisements are framed toward altercentric message orientation only. While egocentric appeals create a greater perception of product quality regardless of the beneficiary, altercentric appeals must be combined with a human-centered approach to avoid an underestimated perception of product quality.

The results of the structural analysis indicate that societal benefits of communal harmony and global wellbeing positively influence altruistic warmth. In turn, personal benefits of uniqueness and product quality encourage egoistic warmth. These findings are consistent with the research in altruism and egoism, which finds that perceptions of societal benefits have a positive relation to pro-environmental attitudes and prosocial emotions [22,52]. By contrast, the perception of personal benefits intrinsically motivates consumers to feel good about themselves. Both types of perceptions motivate consumers to engage in sustainable actions.

The findings support the hypothesis that altruistic warmth significantly contributes to egoistic warmth, which supports the duality of emotional warmth and the conceptualization of impure altruism. Altruism is inevitably connected to egoism [17]. When green products meet consumers' expectations of societal benefits and induce altruistic feelings of warmth, personal advantages such as uniqueness and good quality can be strong differentiating factors in consumers' purchasing decisions for those products [19,24]. Advertisers can assure consumers that purchasing green products brings specific benefits both to society and to themselves, thus conveying an underlying theme of impure altruism $[9,12]$.

As evidenced in this study, effective advertisements that foster sustainable consumption must incorporate both altruistic and egoistic warmth as two key motivators. In fact, connecting "feeling good" and "doing good" has proven to be an extremely effective marketing strategy [9,53]. Rant Clothing, an Australian ethical and sustainable fashion label, is a good example of how linking altruistic and egoistic warmth can add value to consumers' shopping experiences. Rant Clothing, which is locally made and supports small businesses in its industry, uses the slogan "Feel good and enjoy building a wardrobe that showcases the beauty of natural fibres and is made with a conscience" [54]. Rant Clothing has implemented its "feel-good marketing" successfully by emphasizing personal style, meaningfulness, and fashion choices that look good, feel good, and do good.

\subsection{Limitations and Future Research}

Our results come with certain limitations. Specifically, the consumption of clothing itself appears to be a private matter, even in green or ethical apparel purchases. Presumably, incorporating self-benefit and self-expression into green apparel advertisements might create elevated effects for the perceived uniqueness and product quality. Further, Andreoni's [6] theory of warm-glow giving explains impure altruism in the provision of public goods, not private goods. As this study focuses on the concept of green purchases and sustainability as a feature of private consumption, we acknowledge that there is a difference between Andreoni's [6] warm-glow (provision of public goods) and our study's conceptualized impure altruism (private goods). To generalize the results of this study in other settings, future studies should consider gathering the data using different public goods or service categories, such as a gift for charity, humanitarian aid, technology and electronics, household products, tourism, and restaurant services. Replicating this study in other contexts would ensure its external validity.

Second, the quasi-experimental design in this study lacks a control group and thus is subject to concerns regarding causal inferences and internal validity [55]. We attempt to control such potential bias by randomly assigning participants to the experimental conditions [37]. Nevertheless, we recognize the shortcomings of the study design without a control group. Future studies can replicate this research with control groups to reduce this threat to validity.

Finally, future research can extend the concept of impure altruism by testing the effectiveness of various uses of feel-good marketing strategies, such as personal statements to the world and ethical competitive advantage in terms of creating brand value, product affordability, or reputational advantage. Another fruitful extension of this research would be to investigate the effect of personalization in 
promoting green products (e.g., sustainable design, color, materials, and ecofriendly packaging) and determine if customizing green products builds brand awareness and advocacy by better accommodating unique needs of the self.

\subsection{Theoretical Contribution and Conclusions}

This study contributes to the development of sustainability and social marketing communication in two ways. First, the study improves previous insights regarding the role of egocentric and altercentric appeals by incorporating the importance of human beneficiaries in green advertising. Second, this study offers another theoretical groundwork for understanding the impact of altruism, egoism, and impure altruism on green advertising, explaining how altruistic motivation contributes to egoistic warmth and promotes consumers' intentions to purchase green products. By integrating Andreoni's [6] theory of warm-glow giving, this empirically tested model of impure altruism can serve as an extension of a discrete model of altruism and egoism on sustainable behavior.

Tackling sustainability requires a strategic approach that creates positive emotions and builds high levels of brand recognition and consumer satisfaction. We recommend that green apparel retailers adopt feel-good marketing strategies to publicize the benefits of a sustainable lifestyle. Doing so ultimately helps to increase green purchases.

Author Contributions: Conceptualization, investigation, methodology, formal analysis, visualization, and writing—original draft, S.Y.S.; conceptualization, methodology, supervision, writing—review and editing, Y.-K.K.

Conflicts of Interest: The authors declare no conflict of interest.

\section{References}

1. Park, K.; Lee, S.S. The Role of Beneficiaries' Group Identity in Determining Successful Appeal Strategies for Charitable Giving. Psychol. Mark. 2015, 32, 1117-1132. [CrossRef]

2. Chun-Tuan, C.; Yu-Kang, L. The 'I' of the beholder. Int. J. Advert. 2011, 30, 447-470.

3. Batson, C.D. Altruism in Humans; Oxford University Press: New York, NY, USA, 2011.

4. Davis, M.H. History and definitions. In Empathy: A Social Psychological Approach; Harvey, J., Ed.; Westview Press: Boulder, CO, USA, 1994; pp. 1-22.

5. Cialdini, R.B. Altruism or Egoism? That Is (Still) the Question. Psychol. Inq. 1991, 2, 124-126. [CrossRef]

6. Andreoni, J. Impure altruism and donations to public goods: A theory of warm-glow giving. Econ. J. 1990, 100, 464-477. [CrossRef]

7. Lilley, A.; Slonim, R. The price of warm glow. J. Public Econ. 2014, 114, 58-74. [CrossRef]

8. Royne, M.B.; Martinez, J.; Oakley, J.; Fox, A.K. The Effectiveness of Benefit Type and Price Endings in Green Advertising. J. Advert. 2012, 41, 85-102. [CrossRef]

9. Song, S.Y.; Kim, Y.-K. A Human-Centered Approach to Green Apparel Advertising: Decision Tree Predictive Modeling of Consumer Choice. Sustainability 2018, 10, 3688. [CrossRef]

10. Thorisdottir, T.S.; Johannsdottir, L. Sustainability within Fashion Business Models: A Systematic Literature Review. Sustainability 2019, 11, 2233. [CrossRef]

11. Kareklas, I.; Carlson, J.R.; Muehling, D.D. The Role of Regulatory Focus and Self-View in "Green" Advertising Message Framing. J. Advert. 2012, 41, 25-39. [CrossRef]

12. Cheung, W.Y.; Luke, M.A.; Maio, G.R. On attitudes towards humanity and climate change: The effects of humanity esteem and self-transcendence values on environmental concerns. Eur. J. Soc. Psychol. 2014, 44, 496-506. [CrossRef]

13. Hawkins, H.; Best, A.; Coney, K. Consumer Behaviour: Segmentation Customers by Demographic Profile; McGraw-Hill: New York, NY, USA, 2001.

14. Kim, N. Advertising strategies for charities. Int. J. Advert. 2014, 33, 707-724. [CrossRef]

15. Nowak, M.A.; Roch, S. Upstream reciprocity and the evolution of gratitude. Proc. R. Soc. Lond. B Biol. Sci. 2007, 274, 605-610. [CrossRef] [PubMed]

16. Cialdini, R.B.; Brown, S.L.; Lewis, B.P.; Luce, C.; Neuberg, S.L. Reinterpreting the empathy-altruism relationship: When one into one equals oneness. JPSP 1997, 73, 481-494. [CrossRef] 
17. Ryan, T.A. The Role of Beliefs in Purchase Decisions: A Look at Green Purchase Behavior and Altruism. Ph.D. Thesis, University of Minnesota, Minneapolis, MN, USA, 2014.

18. White, K.; Peloza, J. Self-Benefit Versus Other-Benefit Marketing Appeals: Their Effectiveness in Generating Charitable Support. J. Mark. 2009, 73, 109-124. [CrossRef]

19. Halepete, J.; Littrell, M.; Park, J. Personalization of fair trade apparel: Consumer attitudes and intentions. Cloth. Text. Res. J. 2008, 27, 143-160. [CrossRef]

20. Schwartz, S.H. A Proposal for Measuring Value Orientations Across Nations. 2003. Available online: https://pdfs.semanticscholar.org/376a/d809f1313cb41dfcffa8bd180949c273f8c2.pdf (accessed on 16 October 2019).

21. Hedlund, T. The impact of values, environmental concern, and willingness to accept economic sacrifices to protect the environment on tourists' intentions to buy ecologically sustainable tourism alternatives. Tour. Hosp. Res. 2011, 11, 278-288. [CrossRef]

22. Song, S.Y.; Kim, Y.-K. Theory of Virtue Ethics: Do Consumers' Good Traits Predict Their Socially Responsible Consumption? J. Bus. Ethics 2018, 152, 1159-1175. [CrossRef]

23. Pinto, D.C.; Nique, W.M.; Añaña, E.d.S.; Herter, M.M. Green consumer values: How do personal values influence environmentally responsible water consumption? Int. J. Consum. Stud. 2011, 35, 122-131. [CrossRef]

24. Kozlowski, A.; Bardecki, M.; Searcy, C. Tools for Sustainable Fashion Design: An Analysis of Their Fitness for Purpose. Sustainability 2019, 11, 3581. [CrossRef]

25. Liljedal, K.T.; Dahlén, M. Consumers' response to other consumers' participation in new product development. J. Mark. Commun. 2018, 24, 217-229. [CrossRef]

26. Hansen, K.T. Other people's clothes? The international second-hand clothing trade and dress practices in Zambia. Fash. Theory 2000, 4, 245-274. [CrossRef]

27. Littrell, M.A.; Jin Ma, Y.; Halepete, J. Generation X, baby boomers, and swing: Marketing fair trade apparel. J. Fash. Mark. Manag. Int. J. 2005, 9, 407-419. [CrossRef]

28. Cowherd, D.M.; Levine, D.I. Product quality and pay equity between lower-level employees and top management: An investigation of distributive justice theory. Adm. Sci. Q. 1992, 37, 302-320. [CrossRef]

29. Hartmann, P.; Ibáñez, V.A.; Sainz, F.J.F. Green branding effects on attitude: Functional versus emotional positioning strategies. Mark. Intell. Plan. 2005, 23, 9-29. [CrossRef]

30. Ku, H.-H.; Kuo, C.-C.; Wu, C.-L.; Wu, C.-Y. Communicating Green Marketing Appeals Effectively: The Role of Consumers' Motivational Orientation to Promotion versus Prevention. J. Advert. 2012, 41, 41-50. [CrossRef]

31. Kareklas, I.; Carlson, J.R.; Muehling, D.D. "I Eat Organic for My Benefit and Yours": Egoistic and Altruistic Considerations for Purchasing Organic Food and Their Implications for Advertising Strategists. J. Advert. 2014, 43, 18-32. [CrossRef]

32. Abeele, P.V.; MacLachlan, D.L. Process tracing of emotional responses to TV ads: Revisiting the warmth monitor. J. Cons. Res. 1994, 20, 586-600. [CrossRef]

33. Aaker, D.A.; Stayman, D.M.; Hagerty, M.R. Warmth in Advertising-Measurement, Impact, and Sequence Effects. J. Cons. Res. 1986, 12, 365-381. [CrossRef]

34. Gao, Y.L.; Mattila, A.S. Improving consumer satisfaction in green hotels: The roles of perceived warmth, perceived competence, and CSR motive. Int. J. Hosp. Manag. 2014, 42, 20-31. [CrossRef]

35. Griskevicius, V.; Tybur, J.M.; Van den Bergh, B. Going green to be seen: Status, reputation, and conspicuous conservation. JPSP 2010, 98, 392. [CrossRef]

36. Fredrickson, B.L. The Role of Positive Emotions in Positive Psychology: The Broaden-and-Build Theory of Positive Emotions. Am. Psychol. 2001, 56, 218-226. [CrossRef] [PubMed]

37. Cook, T.D.; Campbell, D.T. Quasi-Experimentation: Design and Analysis for Field Settings; Rand McNally: Chicago, IL, USA, 1979.

38. Chang, C. Feeling Ambivalent About Going Green. J. Advert. 2011, 40, 19-31. [CrossRef]

39. Adams, T.; Bezner, J.; Steinhardt, M. The Conceptualization and Measurement of Perceived Wellness: Integrating Balance Across and Within Dimensions. Am. J. Health Promot. 1997, 11, 208-218. [CrossRef] [PubMed]

40. Argo, J.J.; Popa, M.; Smith, M.C. The sound of brands. J. Mark. 2010, 74, 97-109. [CrossRef]

41. Kim, B.H.; Han, S.; Yoon, S. Advertising creativity in Korea. J. Advert. 2010, 39, 93-108. [CrossRef] 
42. Chandrashekaran, R. The influence of redundant comparison prices and other price presentation formats on consumers' evaluations and purchase intentions. J. Retail. 2004, 80, 53-66. [CrossRef]

43. Grewal, D.; Monroe, K.B.; Krishnan, R. The effects of price-comparison advertising on buyers' perceptions of acquisition value, transaction value, and behavioral intentions. J. Mark. 1998, 62, 46-59.

44. Aaker, D.A.; Stayman, D.M.; Vezina, R. Identifying Feelings Elicited by Advertising. Psychol. Mark. 1988, 5, 1-16. [CrossRef]

45. Rosenberg, M. Rosenberg self-esteem scale (RSE). In Acceptance and Commitment Therapy: Measures Package; Princeton University Press: Princeton, NJ, USA, 1965.

46. Shiota, M.N.; Keltner, D.; John, O.P. Positive emotion dispositions differentially associated with Big Five personality and attachment style. J. Posit. Psychol. 2006, 1, 61-71. [CrossRef]

47. Dodds, W.B.; Monroe, K.B.; Grewal, D. Effects of price, brand, and store information on buyers' product evaluations. J. Mark. Res. 1991, 28, 307-319.

48. Hair, J.J.; Black, W.C.; Babin, B.J.; Anderson, R.E. Multivariate Data Analysis, 7th ed.; Pearson Prentice Hall: New York, NY, USA, 2009.

49. Nunnally, J.C.; Bernstein, I. Psychometric Theory; McGrew-Hall: New York, NY, USA, 1994.

50. Fornell, C.; Larcker, D.F. Evaluating structural equation models with unobservable variables and measurement error. J. Mark. Res. 1981, 18, 39-50. [CrossRef]

51. Hatcher, L. Advanced statistics in Research: Reading, Understanding, and Writing Up Data Analysis Results; ShadowFinch Media, LLC: Saginaw, MI, USA, 2013.

52. Mikulincer, M.E.; Shaver, P.R. Prosocial Motives, Emotions, and Behavior: The Better Angels of Our Nature; American Psychological Association: Washington, DC, USA, 2010.

53. Barendregt, B.; Jaffe, R. Green Consumption: The Global Rise of Eco-Chic; Bloomsbury Publishing: New York, NY, USA, 2014.

54. Rant Clothing. Our Story. Available online: http://www.rantclothing.com.au/our-story/ (accessed on 23 March 2015).

55. Shadish, W.R.; Cook, T.D.; Campbell, D.T. Experimental and Quasi-Experimental Designs for Generalized Causal Inference; Houghton Miffin Company: New York, NY, USA, 2002.

(C) 2019 by the authors. Licensee MDPI, Basel, Switzerland. This article is an open access article distributed under the terms and conditions of the Creative Commons Attribution (CC BY) license (http://creativecommons.org/licenses/by/4.0/). 